\title{
Effect of Calcium and Sodium lons in Soft Clay Using Electrokinetic Stabilisation Technique
}

\author{
Nurul Syakeera Nordin ${ }^{1, a}$, Saiful Azhar Ahmad Tajudin²,b, \\ Aeslina Abdul Kadir ${ }^{3, c}$, Riduan Yunus ${ }^{4}$, Mohamad Azim Mohammad Azmi ${ }^{5}$ \\ and Mohamed Nur Shafiq Mohamed Hanif ${ }^{6}$
}

\author{
${ }^{1,2,3,4,5,6}$ Faculty of Civil and Environmental Engineering, Universiti Tun Hussein Onn Malaysia, \\ 86400, Parit Raja, Batu Pahat, Johor, Malaysia
}

agf120033@siswa.uthm.edu.my, bsaifulaz@uthm.edu.my, caeslina@uthm.edu.my

\begin{abstract}
Keywords: electrokinetic stabilisation technique, soft clay, calcium, sodium, stainless steel.
\end{abstract}
\begin{abstract}
Abtract. Electrokinetic Stabilisation (EKS) technique is a combination process of electroosmosis and chemical grouting. This study involves the investigation on the EKS technique performances in stabilising soft clay soils. Stabilising agents will assist the EKS technique by inducing it to the soil under direct current and its movements which is governed by the principle of electrokinetic (EK). The objective of this research is to study the effectiveness of EKS technique in increasing the strength of soft clays. Two reactors were set up by using $1.0 \mathrm{M}$ of calcium chloride $\left(\mathrm{CaCl}_{2}\right)$, sodium silicate $\left(\mathrm{Na}_{2} \mathrm{SiO}_{3}\right)$ as the electrolyte and stainless steel plates as the electrodes. EKS technique was being performed for 21 days period of time with a constant voltage gradient $(50 \mathrm{~V} / \mathrm{m})$. This technique was carried out in two phases where the difference between them is a combination of the stabilising agent. The two combinations of stabilising agents in phase 1 and phase 2 were $\mathrm{CaCl}_{2}-$ distilled water (DW) and $\mathrm{CaCl}_{2}-\mathrm{Na}_{2} \mathrm{SiO}_{3}$, respectively. The difference was, one was using distilled water while the other was using $\mathrm{Na}_{2} \mathrm{SiO}_{3}$. Results of the strength, liquid limit (LL), plastic limit (PL), plasticity index (PI), $\mathrm{pH}$ and ion concentration test towards untreated and treated soil were presented. Showing the strength of treated soil for both phases was increasing near the cathode section with $27.83 \mathrm{kPa}$ and $27.67 \mathrm{kPa}$. LL and PI for treated soil showed the highest value which occurred near the cathode, while PL seems consistant with the values from untreated soil. The Calcium $\left(\mathrm{Ca}^{+}\right)$and sodium $\left(\mathrm{Na}^{+}\right)$concentrations in soil were increasing compared to the untreated soil, hence it has proven that the application of stabilisers in EK treatment is more effective in increasing the strength and the stability of soils.
\end{abstract}

\section{Background}

EKS is the combination process of electroosmosis and chemical grouting and it is most effective for silty and clayey soils because of its low hydraulic conductivity [1,2]. Basically, this technique is to improve the volume stability of soil around and beneath the foundation. This technique involves applying an electrical current across the soil mass to boost the chemical migration from the injection point with the purpose of reacting beneficially with the soil to bring about an improvement in its properties. The advantage by using EKS instead of traditional mix-in-place chemical stabilisation is that the technique allows for remote treatment through soil without any excavation works [2]. The EKS technique can be enhanced by the use of some non-toxic stabilising agents such as lime or calcium chloride solutions. These chemical solutions can be fed at the anode or the cathode depending on the ions to be transferred into the soil. The addition of these chemical stabilisers will alter some properties of the soil such as texture, plasticity, compressibility and permeability. Hence, it can be very effective in improving soil characteristics by reducing the amount of clay size particles and increasing the shear strength [5]. 


\section{Method and Material}

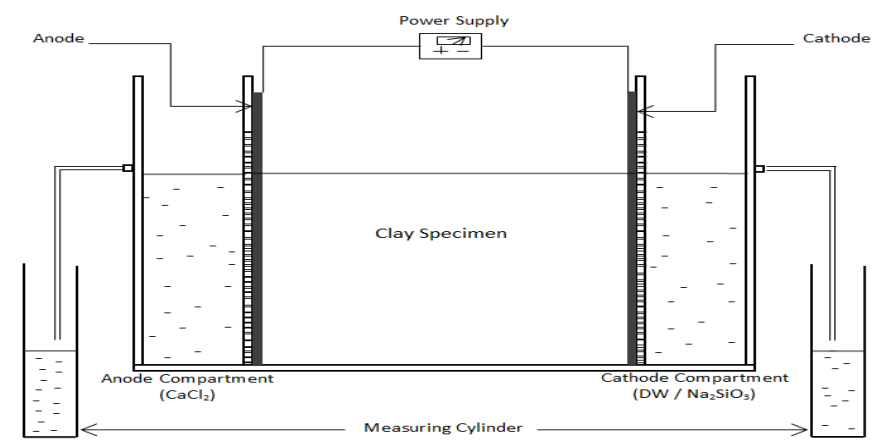

Fig. 1 Schematic diagram of EKS test rig

The EKS test rig was designed for this research. Electrode, electrolyte and stainless steel plate were placed as shown in Fig. 1. For the first phase $\left(\mathrm{CaCl}_{2}-\mathrm{DW}\right), 1.0 \mathrm{M}$ of $\mathrm{CaCl}_{2}$ solution and DW were fed at the anode and cathode compartment, respectively. While $1.0 \mathrm{M}$ of $\mathrm{CaCl}_{2}$ and $\mathrm{Na}_{2} \mathrm{SiO}_{3}$ solution were fed at the anode and cathode compartment, respectively in the second phase $\left(\mathrm{CaCl}_{2}\right.$ $\left.\mathrm{Na}_{2} \mathrm{SiO}_{3}\right)$. A constant voltage gradient $(50 \mathrm{~V} / \mathrm{m})$ was applied to the soil sample as suggested by Mitchell \& Soga [3] and the experiment was performed for 21 days period of time. Soil samples were dried in the oven for 24 hours. The dried sample was ground using grinder machine to get very fine material that would pass $425 \mu \mathrm{m}$ sieve. The slurry sample was prepared by mixing the soil samples with distilled water to achieve $90 \%$ of water content. The water content of slurry was chosen based on 1.5 times of liquid limit (LL). Then, the slurry sample was placed inside the main compartment $(278 \times 165 \times 413 \mathrm{~mm})$ and a uniformly distributed load was applied to it by using large strain consolidation to reduce the water content hence making it in a fully saturated condition [6-8]. Hand vane shear test has been used to determine undrained shear strength of soil. As for LL and PL, they were referring to BS 1377 Part 2:1990, while pH was referring to BS Part 3:1990. In determination of ion concentration, atomic absorption analysis was applied to the soil sample by referring to toxicity characteristic leaching procedure method (EPA Test Method 1311).

Soil Classification of Untreated Soil Table 1 shows the current results and results from previous study of soil classification for untreated soft marine clay at Parit Raja. It shows that those current results were in range and similar as reported by Abdurahman [4]. Mitchell and Soga [3] mentioned that if the plastic and liquid limit of soil were in the range of $25-40 \%$ and $30-110 \%$, it is considered as kaolinite soil.

Table 1 Soil classification of untreated soil

\begin{tabular}{ccc}
\hline Soil classification & Current results & Results from previous study \\
& & $20-35 \%$ \\
\hline Plastic limit & $36.07 \%$ & $37-65 \%$ \\
Liquid limit & $60.84 \%$ & $13-31 \%$ \\
Plastic index & $24.77 \%$ & $2.18-2.65$ \\
Specific gravity & 2.60 & - \\
pH & 2.73 & \\
\hline
\end{tabular}

\section{Results for Treated Soil}

The profiles of the average shear strength of treated soil were shown in Fig. 2. It consists of shear strength values of untreated and treated soil for both phases and it shows the trend of strength value for treated sample lie above the control line. The highest strength values occurred near the cathode section ( $270 \mathrm{~mm}$ from anode). This was probably caused by the effect of precipitation by the cementatious gel and water content at the area. The strength variations for $\mathrm{CaCl}_{2}-\mathrm{Na}_{2} \mathrm{SiO}_{3}$ have a similar trend as reported by Ahmad Tajudin [8], where the highest value occurred near the cathode 
section. The profiles were different compared to Liaki [1], where the lowest strength value occurred near the cathode section. This was because no stabilizers had been applied to the EKS technique in the previous study [1] and it clearly shows that the addition of stabilisers has improved the soil characteristic hence increased the shear strength of soil.

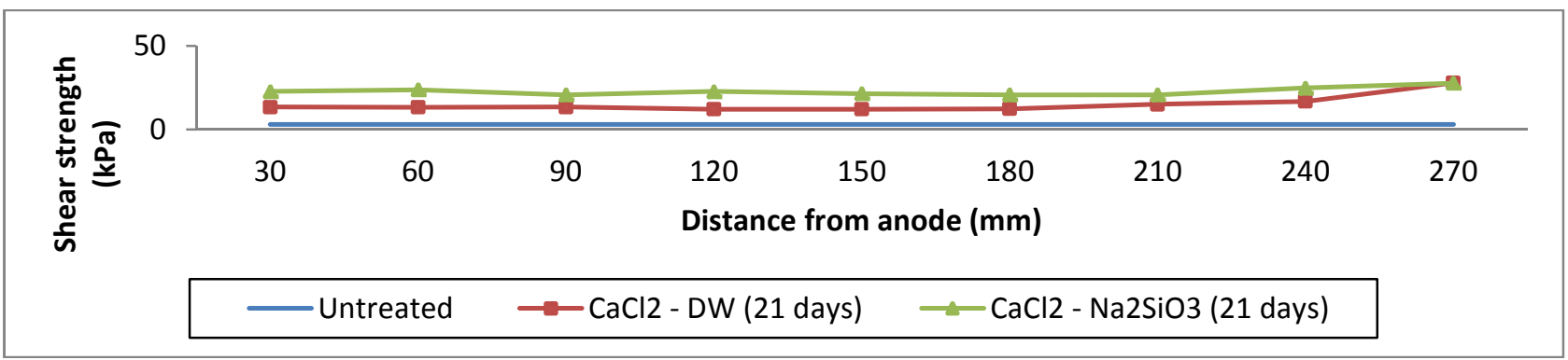

Fig. 2 Shear strength with distance from anode

Table 2 Shear strength for treated soil

\begin{tabular}{lcccccccccc}
\hline $\begin{array}{l}\text { Dist. from anode } \\
\text { (mm) }\end{array}$ & $\mathbf{3 0}$ & $\mathbf{6 0}$ & $\mathbf{9 0}$ & $\mathbf{1 2 0}$ & $\mathbf{1 5 0}$ & $\mathbf{1 8 0}$ & $\mathbf{2 1 0}$ & $\mathbf{2 4 0}$ & $\mathbf{2 7 0}$ \\
\hline $\mathbf{C}_{\mathbf{u}}(\mathbf{k P a})_{\text {CaCl2-DW }}$ & 13.33 & 13.17 & 13.33 & 12.00 & 12.00 & 12.33 & 15.00 & 16.67 & 27.83 \\
$\mathbf{C}_{\mathbf{u}}(\mathbf{k P a})_{\text {CaCl2-Na2SiO3 }}$ & 22.67 & 23.67 & 20.67 & 22.67 & 21.33 & 20.67 & 20.67 & 24.67 & 27.67 \\
\hline
\end{tabular}

The profiles of liquid limit in Fig. 3 shows the lowest value were at $45 \mathrm{~mm}$ from anode and the highest value were at $225 \mathrm{~mm}$ from anode for both phases. The distributions have a similar trend as reported by Ahmad Tajudin [8], where the lowest liquid limit value was occurred near the anode section and the values were slightly increased towards the cathode. The profiles of plastic limit were shown in Fig. 4. The treated soft clay for both phases seems to lie below the control line. It shows the value were decreased at the middle (135 mm from anode) for both phases. According to Ahmad Tajudin [8], the trend of plastic limit distribution lie below the control line for only near the anode and the middle section. At $225 \mathrm{~mm}$ from anode, the trend value was different with the previous researchers but the value was still in range at about $25-40 \%$.

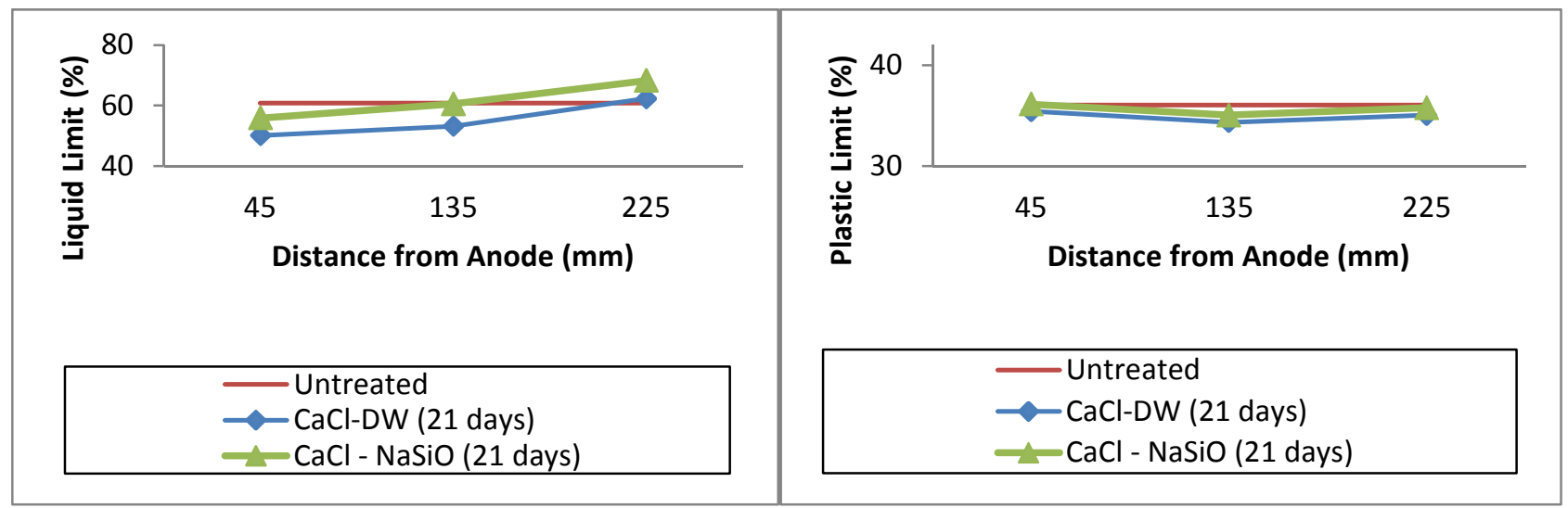

Fig. 3 Liquid limit with distance from anode

Fig. 4 Plastic limit with distance from anode

Fig. 5 shows the plastic index values and it shows that only value at $225 \mathrm{~mm}$ from anode lie above the control line for both phases. While, the lowest value for both phases were occurred at 45 $\mathrm{mm}$ from anode. The distribution shows the different trend with Ahmad Tajudin [8], but these values seem closed at the range of $16-24 \%$ as reported by the researcher. Fig. 6 presents the results of $\mathrm{pH}$ values and the profile shows the values were increased from anode to the cathode. At $45 \mathrm{~mm}$ from anode, $\mathrm{pH}$ values for both phases were considered as highly acidic. The lowest acidic conditions for both phases were occurred near the cathode ( $225 \mathrm{~mm}$ from anode). The increment of $\mathrm{pH}$ values near the cathode was possibly due to the electrolysis process which produced the hydroxide ions. Those variations have a similar trend as reported by Ahmad Tajudin [8], where near 
the anode the $\mathrm{pH}$ value recorded as the lowest value but slightly increased towards the cathode. If no addition of stabiliser was applied in the EK technique as reported by Liaki [1], the highest value of $\mathrm{pH}$ of treated soil will be occurring near the cathode section with $\mathrm{pH} 8-9$.

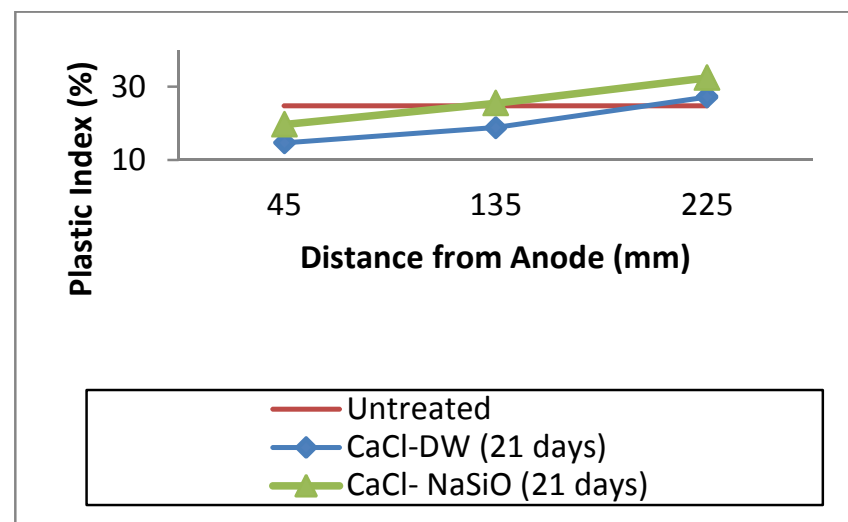

Fig. 5 Plastic index with distance from anode
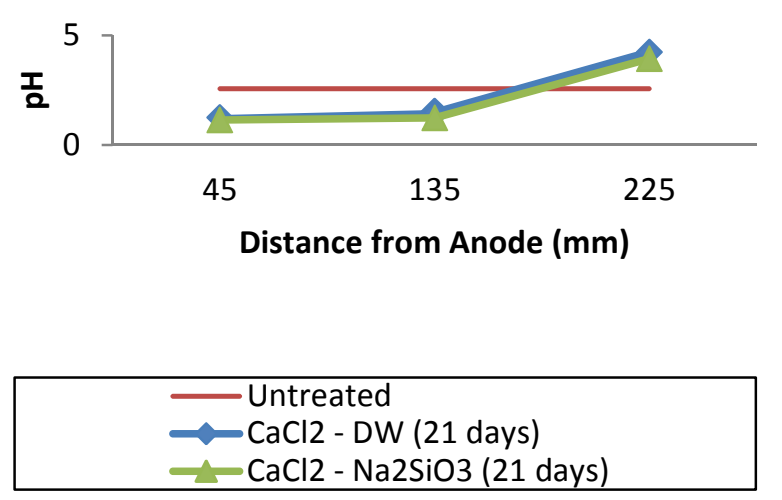

Fig. $6 \mathrm{pH}$ with distance from anode

Since calcium $\left(\mathrm{Ca}^{+}\right)$and sodium $\left(\mathrm{Na}^{+}\right)$ions has been used as the stabilisers towards the soft clay, it is very important to investigate the concentration of those ions after the experiment ended. Fig. 7 shows the $\mathrm{Ca}^{+}$concentration for both phases and the origin concentration for untreated soft clay was $20.47 \mathrm{mg} / \mathrm{l}$. It shows the concentration increased for both phases and the highest value were occurred at $45 \mathrm{~mm}$ from anode. It proves that $\mathrm{Ca}^{+}$ions migrated from anode towards the cathode due to EK process, hence increased the concentration of treated soil in all areas. It has a similar trend with that reported by Ahmad Tajudin [8], where the concentration of $\mathrm{Ca}^{+}$ion declined at the middle (135 $\mathrm{mm}$ from anode) towards the cathode $(225 \mathrm{~mm}$ from anode) when a much longer period was applied. Percolated were occurred during the experiment when it shows the concentration decreased towards the cathode and this can be supported by the results of shear strength. Fig. 8 shows the profiles of $\mathrm{Na}^{+}$concentration and it shows the concentration increased compared to the untreated clay $(1210 \mathrm{mg} / \mathrm{l})$. The increment was in much contrast when compared to $\mathrm{Ca}^{+}$concentration because $\mathrm{Ca}^{+}$ion shows the greatest improvement after the experiment ended. The lower increment value of it attributed to the migration of $\mathrm{Na}^{+}$ions by $\mathrm{EK}$ process and this release is being flushed away from the system at the end of cathode chamber.

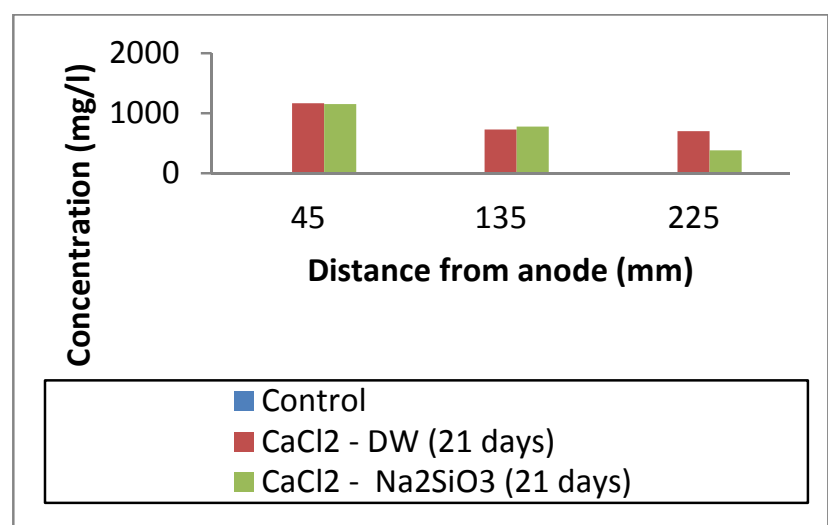

Fig. $7 \mathrm{Ca}^{+}$concentration with distance from anode

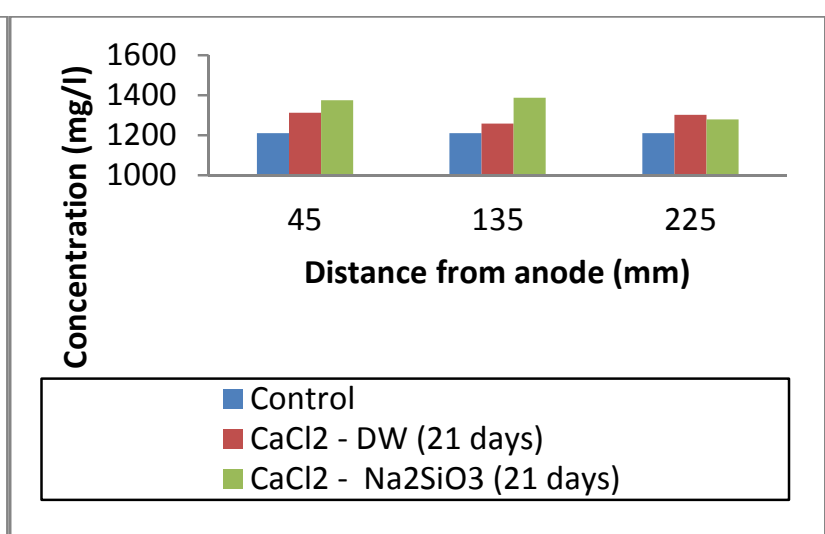

Fig. $8 \mathrm{Na}^{+}$concentration with distance from anode

Table 3 Values of LL, PL, PI, pH and ions concentration

\begin{tabular}{|c|c|c|c|}
\hline Dist. from anode (mm) & 45 & 135 & 225 \\
\hline $\mathrm{LL},(\%)_{C a C l 2-D W}$ & 50.14 & 53.22 & 62.33 \\
\hline $\mathrm{LL},(\%)_{\mathrm{CaCl} 2-\mathrm{Na} 2 \mathrm{SiO} 3}$ & 55.88 & 60.55 & 68.25 \\
\hline $\mathrm{PL},(\%)_{\mathrm{CaCl} 2-\mathrm{DW}}$ & 35.43 & 34.34 & 35.05 \\
\hline $\mathrm{PL},(\%)_{\mathrm{CaCl}-\mathrm{Na} 2 \mathrm{SiO} 3}$ & 36.14 & 35.05 & 35.78 \\
\hline PI, (\%) $)_{C a C l 2-D W}$ & 14.71 & 18.88 & 27.25 \\
\hline
\end{tabular}




\begin{tabular}{|c|c|c|c|}
\hline $\mathrm{PI},(\%)_{\mathrm{CaCl}-\mathrm{Na} 2 \mathrm{SiO} 3}$ & 19.74 & 25.50 & 32.47 \\
\hline $\mathrm{pH},{ }_{C a C l 2-D W}$ & 1.25 & 1.48 & 4.23 \\
\hline $\mathrm{pH},{ }_{\mathrm{CaCl}-\mathrm{Na} 2 \mathrm{SiO} 3}$ & 1.14 & 1.23 & 3.92 \\
\hline $\mathrm{Ca}^{+}(\mathrm{mg} / \mathrm{l})_{\mathrm{CaCl2}-\mathrm{DW}}$ & 1164.00 & 731.80 & 703.80 \\
\hline $\mathrm{Ca}^{+}(\mathrm{mg} / \mathrm{l})_{\mathrm{CaCl} 2-\mathrm{Na} 2 \mathrm{SiO} 3}$ & 1149.00 & 779.30 & 381.30 \\
\hline $\mathrm{Na}^{+}(\mathrm{mg} / \mathrm{l})_{\mathrm{CaCl} 2-\mathrm{DW}}$ & 1313.00 & 1259.00 & 1301.00 \\
\hline $\mathrm{Na}^{+}(\mathrm{mg} / \mathrm{l})_{\mathrm{CaCl2}-\mathrm{Na} 2 \mathrm{SiO} 3}$ & 1375.00 & 1387.00 & 1279.00 \\
\hline
\end{tabular}

\section{Conclusion}

EKS technique was conducted on soft marine clay at Parit Raja by using $\mathrm{CaCl}_{2}$ and $\mathrm{Na}_{2} \mathrm{SiO}_{3}$ as the electrolytes and stainless steel plate as the electrode. It has been running for 21 days and a constant voltage gradient $(50 \mathrm{~V} / \mathrm{m})$ was applied to the soil. The consumption of $\mathrm{CaCl}_{2}-\mathrm{DW}$ and $\mathrm{CaCl}$ $\mathrm{Na}_{2} \mathrm{SiO}_{3}$ as stabilisers into the soil has significantly increased the strength especially in the vicinity of the cathode for both phases. EKS technique has reduced soil water content due to the electroosmosis process which caused an increase of soil pore water pressure, thus increased the shear strength as well. The addition of those stabilisers also decreases the LL and PL of soft clay. This is due to the high acidic environment after the treatment. The $\mathrm{pH}$ values of treated soil shows the soft clay creating an acidic value at the anode and slightly increases to its base value towards the cathode. The $\mathrm{Ca}^{+}$and $\mathrm{Na}^{+}$concentration results make a better understanding regarding to the improvement parameters of soft clay such as strength, LL, PL and $\mathrm{pH}$ when those ions were applied to the system as the stabilising agents.

\section{Acknowledgement}

The author wishes to thank to Universiti Tun Hussein Onn Malaysia for sponsored this research.

\section{References}

[1] C. Liaki, C.D.F. Rogers, D.I. Boardman: Physico-chemical effects on clay due to electromigration using stainless steel electrodes, J Appl Electrochem, (2010) p. 1225-1237.

[2] J.E. Barker, C.D.F. Rogers, D.I. Bordman, J. Peterson: Electrokinetic stabilisation: an overview and case study, Ground Improvement (2004) p. 47-58.

[3] J. K. Mitchell, K. Soga: Fundamentals of Soil Behavior. $3^{\text {rd }}$ ed. Berkeley: University of California, (2005)

[4] M.N. Abdurahman: Short term performance evaluation of a rural road embankment with different reinforcement constructed on soft soil pertaining to vertical settlement, Master of civil engineering, KUiTTHO (2005)

[5] M. Nasim, O. Erwin, C. Gary: A review of electrokinetic treatment technique for improving the engineering characteristic of low permeable problematic soil, Int. J. of GEOMATE, Vol. 2. No. 2. (2011) p. 266-272.

[6] N.S. Nordin, S.A. Ahmad Tajudin, A. Abdul Kadir: Physical properties of treated soft clay by using electrokinetic stabilisation method, Soft Soil Engineering International Conference (2013).

[7] N.S. Nordin, S.A. Ahmad Tajudin, A. Abdul Kadir: Stabilisation of soft soil using electrokinetic stabilisation method, International Journal of Zero Waste Generation (2013)

[8] S.A. Ahmad Tajudin: Electrokinetic Stabilisation of Soft Clay, School of Civil Engineering, University of Birmingham, UK, (2012) 